\title{
Erratum: Flow damping due to stochastization of the magnetic field
}

\author{
K. Ida, M. Yoshinuma, H. Tsuchiya, T. Kobayashi, C. Suzuki, M. Yokoyama, A. Shimizu, K. Nagaoka, S. Inagaki, \\ K. Itoh \& the LHD Experiment Group
}

Nature Communications 6:5816 doi: 10.1038/ncomms6816 (2015); Published 8 Jan 2015; Updated 5 Mar 2015

The affiliation details for A. Isayama, K. Shinohara, P.S. Bawankar, X.L. Huang, M. Ohno, S. Pandya, R. Sano and H. Zhang as part of the LHD Experiment Group were incorrect in this Article. The correct affiliation details for these authors are listed below:

A. Isayama ${ }^{8}$, K. Shinohara ${ }^{8}$, P.S. Bawankar ${ }^{5}$, X.L. Huang ${ }^{5}$, M. Ohno ${ }^{5}$, S. Pandya ${ }^{5}$, R. Sano ${ }^{5}$, H. Zhang $^{5}$

${ }^{5}$ The Graduate University for Advanced Studies, 322-6 Oroshi, Toki, Gifu 509-5292, Japan. ${ }^{8}$ Japan Atomic Energy Agency, Naka, Ibaraki 311-0193, Japan. 